\title{
Correction to: Application of laser-arc hybrid welding of steel for low-temperature service
}

\author{
Ivan Bunaziv ${ }^{1} \cdot$ Odd M. Akselsen $^{1,2} \cdot$ Jan Frostevarg $^{3} \cdot$ Alexander F. H. Kaplan $^{3}$
}

Published online: 21 March 2019

(C) Springer-Verlag London Ltd., part of Springer Nature 2019

\section{Correction to: The International Journal of Advanced Manufacturing Technology} https://doi.org/10.1007/s00170-019-03304-1

The original version of this article contained several mistakes.

Due to technical problems at the typesetter, author corrections were not carried out.

The original article has been corrected.

Publisher's note Springer Nature remains neutral with regard to jurisdictional claims in published maps and institutional affiliations.

The online version of the original article can be found at https://doi.org/ 10.1007/s00170-019-03304-1

Ivan Bunaziv

ivan.bunaziv@ntnu.no

1 Department of Mechanical and Industrial Engineering, Norwegian University of Science and Technology, Richard Birkelands vei 2B, NO-7491 Trondheim, Norway

2 SINTEF Industry, P.O. Box 4760, Sluppen, NO-7465 Trondheim, Norway

3 Department of Engineering Sciences and Mathematics, Luleå University of Technology, SE-97187 Luleå, Sweden 